\title{
Examination of Nudging Schemes in the Simulation of Meteorology for Use in Air Quality Experiments: Application in the Great Lakes Region $\mathscr{O}$
}

\author{
M. TAlat Odman, ${ }^{\mathrm{a}}$ Andrew T. White, ${ }^{\mathrm{b}}$ KeVin Doty, ${ }^{\mathrm{b}}$ Richard T. MCNider, ${ }^{\mathrm{c}}$ \\ Arastoo Pour-Biazar, ${ }^{\mathrm{b}}$ Momei Qin, ${ }^{\mathrm{a}}$ Yongtao Hu, ${ }^{\mathrm{a}}$ Eladio KNIPPING, ${ }^{\mathrm{d}}$ Y. Wu, ${ }^{\mathrm{b}}$ AND \\ BRIGHT DORNBLASER ${ }^{\mathrm{e}}$

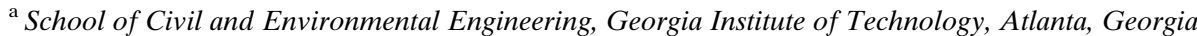 \\ ${ }^{\mathrm{b}}$ Earth System Science Center, University of Alabama in Huntsville, Huntsville, Alabama \\ ${ }^{\mathrm{c}}$ Department of Atmospheric Science, University of Alabama in Huntsville, Huntsville, Alabama \\ ${ }^{\mathrm{d}}$ Electric Power Research Institute, Washington, DC \\ ${ }^{\mathrm{e}}$ Texas Commission on Environmental Quality, Austin, Texas
}

(Manuscript received 15 August 2018, in final form 23 August 2019)

\begin{abstract}
High levels of ozone have been observed along the shores of Lake Michigan for the last 40 years. Models continue to struggle in their ability to replicate ozone behavior in the region. In the retrospective way in which models are used in air quality regulation development, nudging or four-dimensional data assimilation (FDDA) of the large-scale environment is important for constraining model forecast errors. Here, paths for incorporating large-scale meteorological conditions but retaining model mesoscale structure are evaluated. For the July 2011 case studied here, iterative FDDA strategies did not improve mesoscale performance in the Great Lakes region in terms of diurnal trends or monthly averaged statistics, with overestimations of nighttime wind speed remaining as an issue. Two vertical nudging strategies were evaluated for their effects on the development of nocturnal low-level jets (LLJ) and their impacts on air quality simulations. Nudging only above the planetary boundary layer, which has been a standard option in many air quality simulations, significantly dampened the amplitude of LLJ relative to nudging only above a height of $2 \mathrm{~km}$. While the LLJ was preserved with nudging only above $2 \mathrm{~km}$, there was some deterioration in wind performance when compared with profiler networks above the jet between $500 \mathrm{~m}$ and $2 \mathrm{~km}$. In examining the impact of nudging strategies on air quality performance of the Community Multiscale Air Quality model, it was found that performance was improved for the case of nudging above $2 \mathrm{~km}$. This result may reflect the importance of the LLJ in transport or perhaps a change in mixing in the models.
\end{abstract}

\section{Introduction}

High levels of ozone $\left(\mathrm{O}_{3}\right)$ along the shores of Lake Michigan have been a major problem for air quality agencies in the region for nearly 40 years (Lyons and Cole 1976; Foley et al. 2011). As an example, several counties located in the Milwaukee (Wisconsin)-Chicago (Illinois)-Gary (Indiana) urban corridor along Lake Michigan that are densely populated areas with a variety of emission sources have been violating the 2008promulgated 0.075 parts per million (ppm) National

Supplemental information related to this paper is available at the Journals Online website: https://doi.org/10.1175/JAMC-D-180206.s1.

Corresponding author: M. Talat Odman, odman@gatech.edu
Ambient Air Quality Standard (NAAQS) for 8-h $\mathrm{O}_{3}$ (EPA 2018). Those counties are in violation of the more stringent $20158-\mathrm{h} \mathrm{O}_{3}$ standard of $0.070 \mathrm{ppm}$. As evidence of concern, the Lake Michigan Air Directors Consortium Organization (LADCO) has continued to sponsor and initiate research to improve understanding and modeling of ozone in the Lake Michigan environment including the recent 2017 Lake Michigan Ozone Study (LMOS). See a recent companion paper to the present study (McNider et al. 2018) for additional background.

Although the mesoscale meteorological behavior near Lake Michigan has received considerable attention, the synoptic conditions have a major impact on the development of mesoscale phenomena such as lake and land breezes that influence coastal ozone enhancements. McNider et al. (2018) discussed the role of overwater 
stability on ozone over Lake Michigan (Cleary et al. 2015) and the important role that surface moisture and soil temperature had on model performance (see also Michelson and Bao 2008).

For many regulatory actions, air quality models are run in a retrospective mode attempting to recreate past air quality episodes. Meteorological models that are run at high resolution (a resolution higher than the rawinsonde network resolution) need to be constrained by large-scale (synoptic) analyses to avoid unconstrained model drift (Stauffer and Seaman 1990, 1994; Stauffer et al. 1991; Shafran et al. 2000) yet not degrade the mesoscale structure and local boundary layer characteristics that are important to air quality simulations (Appel et al. 2014).

Four-dimensional data assimilation (FDDA) has generally improved model performance (Otte 2008; Rogers et al. 2013), but there is still concern that nudging to the large-scale analysis, a technique specifically used in air quality modeling applications to improve meteorological inputs, may be adversely impacting mesoscale structures that are important to air quality but are not resolved in the analysis. Popular choices in the air quality community in the United States for initialization and FDDA include the North American Mesoscale Forecast System (NAM) 12-km analyses and forecasts (https://www.ncdc.noaa.gov/data-access/model-data/modeldatasets/north-american-mesoscale-forecast-system-nam) and the North American Regional Reanalysis (NARR) 32-km product (https://www.ncdc.noaa.gov/data-access/ model-data/model-datasets/north-american-regionalreanalysis-narr) (see Mesinger et al. 2006). The former product will be referred to subsequently as NAM-12. In this paper we employ the NAM analysis within the Weather Research and Forecasting (WRF) Model and WRF-ARW 3.8.1 (Skamarock et al. 2008).

\section{a. Retaining mesoscale model structure while carrying out FDDA}

FDDA refers to efforts to incorporate observed data or analyses into models. This can include many approaches such as variational techniques or Newtonian nudging. While nudging can be used to incorporate small-scale observations, here we examine strategies and techniques for nudging of generally larger-scale observational analyses and their impact on model performance. Early Newtonian nudging FDDA strategies (Stauffer and Seaman 1990) employed a nudging coefficient on the order of $10^{-4} \mathrm{~s}^{-1}$ based on the time scale of the physical phenomena. Being on the order of the Coriolis time scale this magnitude of nudging coefficient was intended to nudge the model to the synoptic-scale features without significantly dampening the mesoscale frequency structure As shown by Appel et al. (2014), nudging to the type of larger-scale analyses mentioned above can alter mesoscale features to some extent. Appel et al. (2014) suggested an iterative approach that was designed to maintain mesoscale structure. In tests in the Chesapeake Bay area, it significantly improved model performance. Below we examine this strategy for a case study for the Great Lakes region.

\section{b. Impact of nudging strategies on low-level jets}

As discussed by McNider et al. (1988), the vertical shear in the low-level jet (LLJ) has a major impact on the rate at which urban or point source plumes grow horizontally overnight. Turbulent theory (Taylor 1921) predicts that near-source plume growth rates are proportional to time $t$ but that as the plume grows to the size of the turbulent eddies plume growth rates slow to $t^{1 / 2}$. However, observations of smelter plumes in Australia at long distances showed that plumes grew at a rate much greater than $t^{1 / 2}$ (Carras and Williams 1981). In the early 1980s, the leading air quality turbulent researchers debated whether it was mesoscale spatial energy (Gifford 1983) or shear (Smith 1983) that was sustaining the growth. McNider et al. (1988) showed that it was mesoscale temporal energy in the LLJ that sheared the plume overnight and sustained the plume growth observed. It was also shown that the LLJ was the dominant mechanism for exporting precursors and ozone out of urban areas in Nashville, Tennessee (Banta et al. 1998); Houston, Texas (McNider and Pour-Biazar 2019); and the Northeast (NESCAUM 2006).

Since the importance of low-level jets to air quality had been demonstrated and models such as WRF contained the requisite physics to produce the LLJ, it was perhaps generally felt that this was no longer a major issue for air quality modeling. However, more recent studies by Godowitch et al. (2011) and Gilliam et al. (2012) indicated that the nudging strategies unique to the air quality community may be inhibiting the development of the LLJ. This was evidently first discussed by Shafran et al. (2000), but no specific details on the impact of the nudging strategies were provided. Our paper examines the development of the LLJ in the Great Lakes area in relation to nudging strategies that are generally employed by the air quality community and the impact of these strategies on air quality. It is also postulated that the inhibition of the LLJ in exporting emissions and precursors out of urban areas may be related to the underestimation of column nitrogen dioxide $\left(\mathrm{NO}_{2}\right)$ in rural areas and overestimation in urban areas relative to satellite column $\mathrm{NO}_{2}$ (Canty et al. 2015). 


\section{Iterative analysis nudging}

Appel et al. (2014), using the coupled WRF-Community Multiscale Air Quality (CMAQ) modeling system, employed an iterative FDDA technique in which an initial large-scale analysis used in the FDDA nudging is replaced by a second nudging field produced by the initial finescale simulation. The Appel et al. (2014) study was trying to capture the finescale details of the Chesapeake Bay area, and similar concerns are perhaps relevant in replicating the finescale meteorological system of the Great Lakes region.

Appel et al. (2014) noted that surface temperature was not well captured with the use of the NAM-12 analysis for finer-scale simulations (4 and $1 \mathrm{~km})$. In addition, the data assimilation technique that aims to improve soil moisture and temperature (Pleim and Gilliam 2009) was ineffective at the finer scales because of the inconsistencies of the NAM-12 analysis with the higher-resolution geography, terrain, land use, and soil data. In their iterative approach, the outputs from the initial finer-scale simulation ( 4 or $1 \mathrm{~km}$ ), produced using the NAM-12 analysis corrected by observations, are input to a second iteration of the same-scale WRF simulation, instead of the NAM-12 analysis. Observations are merged with the first iteration simulation using FDDA to reduce the model errors. Together with the additional use of detailed SST data from GHRSST (https://www.ghrsst.org/), this approach produced significant improvements in representing the temperature gradients in an application to the Chesapeake Bay (Appel et al. 2014). Here, we explore the iterative approach in our model applications to the Great Lakes region and investigate the effects of subsequent iterations.

\section{a. Initial iteration}

The WRF 3.8.1 as configured in Table 1 was applied to simulate the meteorological conditions in the Great Lakes during July 2011, when high ozone concentrations were observed. The simulation was performed with a 4$\mathrm{km}$-horizontal-resolution domain nested inside a 12-km one (with one-way nesting), and it will be referred to as the initial iteration, first iteration, or iter1. The outer domain covers the entire continental United States as well as a portion of Canada, and the inner domain focuses on the area surrounding the Great Lakes (Fig. 1). Both domains have 34 vertical layers extending from the surface to $50 \mathrm{hPa}$. The 3-hourly NAM-12 analysis product was used to provide initial and lateral boundary conditions for the simulations. In the initial WRF simulation, soil nudging in the Pleim-Xiu land surface model (P-X LSM) (Pleim and Xiu 1995, 2003; Xiu and Pleim 2001) was turned on to indirectly correct biases in
TABLE 1. WRF Model configurations for the 12- and 4-kmhorizontal-resolution domains.

\begin{tabular}{|c|c|c|}
\hline Scheme & $12 \mathrm{~km}$ & $4 \mathrm{~km}$ (the first iteration) \\
\hline Longwave radiation & \multicolumn{2}{|c|}{ RRTMG (Iacono et al. 2008) } \\
\hline Shortwave radiation & \multicolumn{2}{|c|}{ RRTMG } \\
\hline Land surface & \multicolumn{2}{|c|}{$\begin{array}{c}\text { Pleim-Xiu (Xiu and Pleim 2001; Pleim and } \\
\text { Xiu 2003; Pleim and Gilliam 2009; } \\
\text { Gilliam and Pleim 2010) }\end{array}$} \\
\hline Land-use database & \multicolumn{2}{|c|}{ National Land Cover Database 2011} \\
\hline Cumulus & \multicolumn{2}{|c|}{ Kain-Fritsch (Kain 2004) } \\
\hline Microphysics & \multicolumn{2}{|c|}{ Morrison (2 moments) (Morrison et al. 2009) } \\
\hline PBL & \multicolumn{2}{|c|}{ ACM2 (Pleim 2007) } \\
\hline Surface nudging & \multicolumn{2}{|c|}{ Off } \\
\hline Grid nudging & Above the PBL & Off \\
\hline Soil nudging & \multicolumn{2}{|r|}{ On } \\
\hline
\end{tabular}

2-m ambient air temperature $\mathrm{T} 2$ and relative humidity RH by dynamic adjustment of soil moisture (Pleim and Xiu 2003) and deep soil temperature (Pleim and Gilliam 2009), using the National Centers for Environmental Prediction Automated Data Processing (NCEP ADP) Global Surface Observational Weather Data (ds461.0, referred to as SURFOBS in the following sections). In addition, grid nudging of winds, temperature, and moisture above the planetary boundary layer (PBL) consisting of a blend of NAM-12 data with NCEP ADP Global Upper Air Observational Weather Data (ds351.0, referred to as UPAIROBS in the following sections) was performed for the $12-\mathrm{km}$ domain only, with no surface nudging (except soil moisture and temperature nudging) for either domain (see Fig. S1 in the online supplemental material). The simulation period went from 15 June to 1 August 2011, with the first five days used to initialize the deep soil moisture and temperature (Pleim and Gilliam 2009), and an additional 10 days to allow the chemistry to come into equilibrium in the air quality model (thus the first 15 days are not included in the analysis). The simulation used 5.5-day overlapping run segments, with the first $12 \mathrm{~h}$ as the spinup period.

\section{b. Second iteration}

The second WRF simulation, denoted as the second iteration or iter 2 hereinafter, is aimed to improve meteorological simulations at finer scales, following the work of Appel et al. (2014). The second iteration was performed for the 4-km domain only, $\mathrm{T} 2$ from the initial 4-km WRF simulation (iter1), blended with observations available in the NCEP Meteorological Assimilation Data Ingest System (MADIS) and ADP datasets SURFOBS using objective analysis (OBSGRID). The higher-resolution T2, in place of the NAM-12 data used in the first iteration, can lead to more effective reduction of soil temperature and moisture biases by the soil nudging scheme (Appel et al. 2014; Pleim and Gilliam 


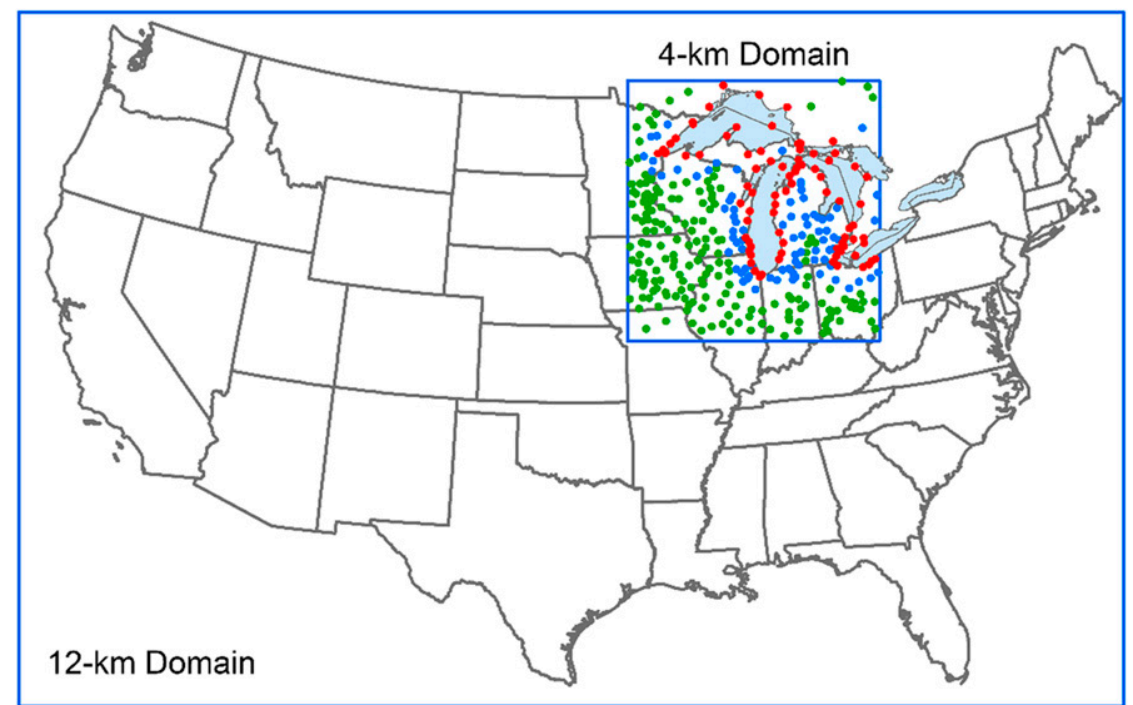

FIG. 1. Schematic of modeling domains used in the study (blue-outlined boxes) with observational sites for model evaluation by three categories - inland (green points), buffer (blue points), and coastal (red points).

2009; Pleim and Xiu 2003), and consequently they optimize the ground-level meteorological fields, such as $\mathrm{T} 2$, in the second iteration (see online supplemental Fig. S1). Other configurations of the WRF Model in the first iteration remained unchanged. Both the first and second iteration were evaluated against the Techniques Development Laboratory U.S. and Canada surface hourly observations (Meteorological Development Laboratory 1987) over the 4-km domain (Fig. 1). The observational sites were grouped into three categories depending on the distance from the site to the shoreline: inland if more than $100 \mathrm{~km}$, buffer if between 20 and $100 \mathrm{~km}$, and coastal if within $20 \mathrm{~km}$ (see Fig. 1).

\section{c. Modified second iteration}

A modified version of the second iteration (referred to as iter $2 m$ ) was conducted with different initial/boundary conditions as detailed in Table 2. In this experiment, more of the WRF outputs from the first iteration, including $\mathrm{T} 2$ and $\mathrm{RH}$, were used in place of NAM-12, to initialize meteorological fields in the second iteration. Paired $t$ tests, with the alternative hypothesis of "the mean of one group is sufficiently different than the mean of the other group" for hourly metrics consisting of absolute bias, root-mean-square error (RMSE), and index of agreement (IOA) were conducted to check whether the modification is able to improve the model performance (lower absolute bias and RMSE and higher IOA) with statistical significance.

\section{d. Evaluation of the second iteration}

The observation-simulation comparison (Fig. 2) reveals that, in the first iteration, high biases of groundlevel wind speed tend to occur during the nighttime and in the early morning [1900-0700 central standard time (CST)] when wind speed is low, with slight overestimation during the daytime, regardless of the location of sites. The biases in surface wind speed could be

TABLE 2. Configurations of the July 2011 simulations for the 4-km domain.

\begin{tabular}{lcccc}
\hline \hline Case & Initial condition & Boundary condition & Soil nudging & Grid nudging \\
\hline iter1 & NAM-12 adjusted by UPAIROBS & 12-km WRF output & $\begin{array}{c}\text { T2 and 2-m specific humidity (Q2) interpolated } \\
\text { from NAM-12 and adjusted by SURFOBS }\end{array}$ \\
iter2 & NAM-12 adjusted by UPAIROBS & 12-km WRF output & $\begin{array}{c}\text { T2 from 4-km WRF output (iter1) with Q2 } \\
\text { from NAM-12, both adjusted by MADIS } \\
\text { and SURFOBS }\end{array}$ & $\begin{array}{c}\text { T2 from 4-km WRF output (iter1), Q2 } \\
\text { calculated using T2 and RH from 4-km }\end{array}$ \\
iter2m & 4-km WRF output (iter1) adjusted by UPAIROBS & WRF output (iter1), both adjusted by \\
& & & MADIS and SURFOBS \\
\hline
\end{tabular}



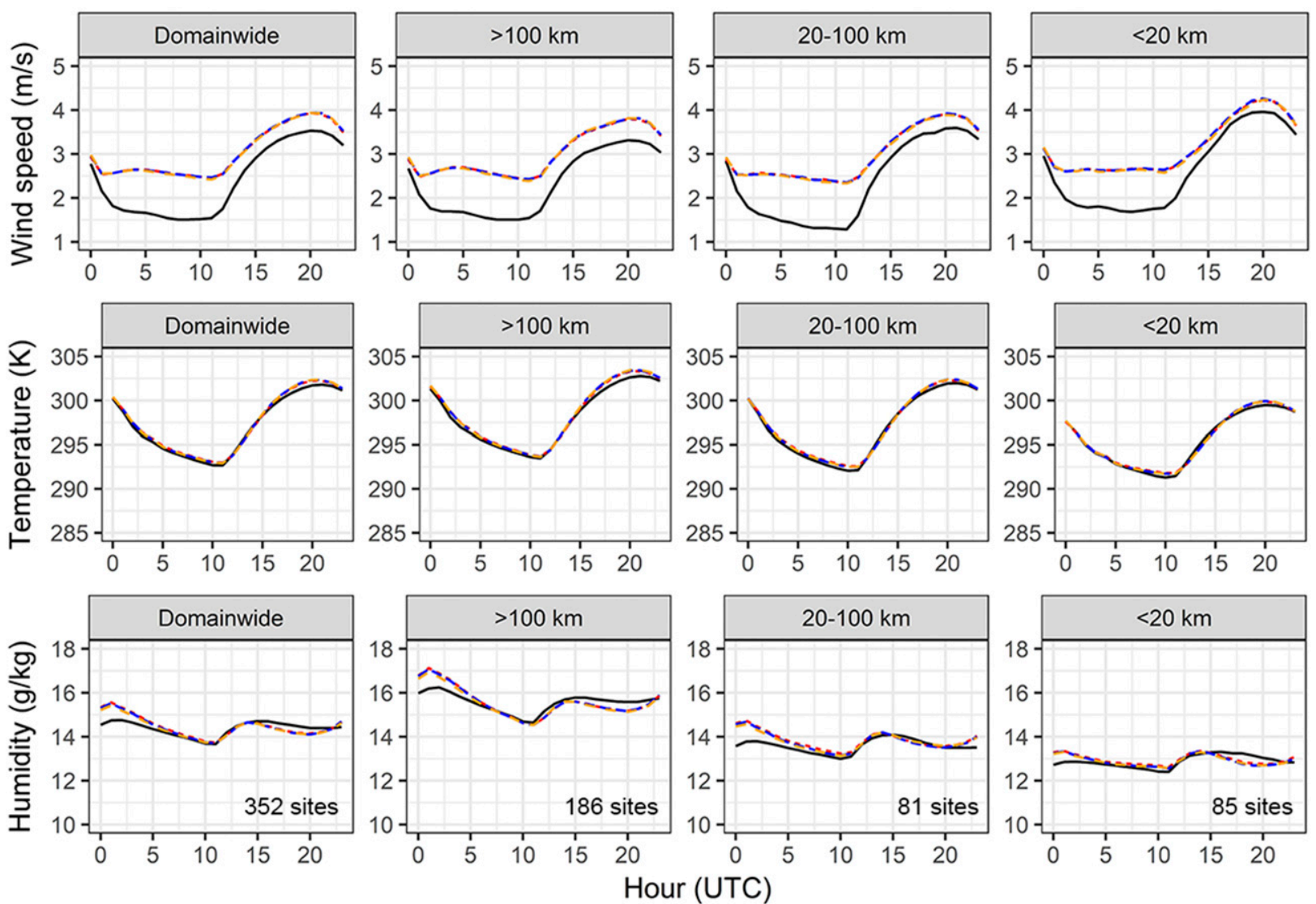

FIG. 2. Diurnal trends of observed (solid line) and simulated wind speed, temperature, and humidity in the first (red dashed line), second (blue dashed line), and modified second (orange dashed line) iterations within the 4-km grid domain shown in Fig. 1 from 1 Jul to 1 Aug 2011 (UTC). The number of observational sites is given for each site category. Note that UTC is $5 \mathrm{~h}$ ahead of local time (CDT); i.e., 1700 UTC corresponds to local noon.

related to PBL parameterization. Zhang and Zheng (2004) in a WRF study of diurnal surface wind speed performance showed that different PBL schemes produced different statistics so that the bias in surface wind speed may be due to issues with too much mixing at night, such as discussed in McNider et al. (2018). The model performs better in temperature and water vapor mixing ratio (humidity hereinafter), though the temperature is biased slightly high in the afternoon, particularly in inland areas. There are negative humidity biases around noon, switching to positive biases at night. The WRF Model successfully captures the variations of meteorological fields across the three sitelocation categories, that is, higher daytime wind speed and lower temperature and humidity at coastal sites than at inland sites, but with similar hourly statistics against observations (Table 3).

The second iteration yields almost identical diurnal variations of wind speed, temperature, and humidity as the first one (Fig. 2), with significant high biases during the nighttime as a remaining issue. The second iteration does not show significant improvements against the first iteration, in terms of the performance statistics (Table 3), which is consistent with the diurnal trend plots. The paired $t$ tests even show deteriorating performance on wind speed and coastal temperature with respect to iter1, whereas simulated humidity seems to be improved (Table 4). Wind speed, temperature, and humidity in the second iteration are biased high (positive bias), on average by $0.64 \mathrm{~m} \mathrm{~s}^{-1}, 0.28 \mathrm{~K}$, and $0.06 \mathrm{~g} \mathrm{~kg}^{-1}$, respectively, with higher domainwide IOA for temperature and humidity $(0.88$ and 0.88$)$ than for wind speed (0.61).

\section{e. Impact of the modified second iteration}

Relative to the second iteration, the modified second iteration did not substantially change the simulated 
TABLE 3. Hourly statistics for the simulated wind speed, wind direction, temperature, and humidity fields in the first (iter1), second (iter2), and modified second (iter2m) iterations over the 4-km domain from 1 Jul to 1 Aug 2011 (UTC).

\begin{tabular}{|c|c|c|c|c|c|c|c|c|c|c|c|c|}
\hline \multirow[b]{2}{*}{ Case } & \multicolumn{3}{|c|}{ Domainwide } & \multicolumn{3}{|c|}{$>100 \mathrm{~km}$} & \multicolumn{3}{|c|}{$20-100 \mathrm{~km}$} & \multicolumn{3}{|c|}{$<20 \mathrm{~km}$} \\
\hline & Bias & RMSE & $\mathrm{IOA}^{\mathrm{a}}$ & Bias & RMSE & $\mathrm{IOA}^{\mathrm{a}}$ & Bias & RMSE & $\mathrm{IOA}^{\mathrm{a}}$ & Bias & RMSE & $\mathrm{IOA}^{\mathrm{a}}$ \\
\hline \multicolumn{13}{|c|}{ Wind speed $\left(\mathrm{m} \mathrm{s}^{-1}\right)$} \\
\hline iter1 & 0.63 & 1.69 & 0.61 & 0.69 & 1.67 & 0.60 & 0.63 & 1.65 & 0.58 & 0.52 & 1.74 & 0.59 \\
\hline iter2 & 0.64 & 1.69 & 0.61 & 0.69 & 1.67 & 0.60 & 0.63 & 1.65 & 0.58 & 0.54 & 1.75 & 0.59 \\
\hline iter $2 \mathrm{~m}$ & 0.63 & 1.70 & 0.61 & 0.69 & 1.68 & 0.60 & 0.61 & 1.66 & 0.57 & 0.51 & 1.74 & 0.59 \\
\hline \multicolumn{13}{|c|}{ Wind direction $\left({ }^{\circ}\right)$} \\
\hline iter1 & 7.90 & & & 9.82 & & & 8.12 & & & 3.71 & & \\
\hline iter2 & 7.96 & & & 9.98 & & & 8.35 & & & 3.46 & & \\
\hline iter $2 \mathrm{~m}$ & 7.82 & & & 9.67 & & & 8.00 & & & 3.69 & & \\
\hline \multicolumn{13}{|c|}{ Temperature (K) } \\
\hline iter1 & 0.27 & 1.97 & 0.88 & 0.36 & 1.85 & 0.85 & 0.25 & 1.90 & 0.81 & 0.12 & 2.15 & 0.88 \\
\hline iter2 & 0.28 & 1.97 & 0.88 & 0.38 & 1.85 & 0.86 & 0.22 & 1.91 & 0.81 & 0.10 & 2.16 & 0.88 \\
\hline iter $2 \mathrm{~m}$ & 0.28 & 1.98 & 0.88 & 0.38 & 1.86 & 0.85 & 0.23 & 1.92 & 0.80 & 0.11 & 2.18 & 0.88 \\
\hline \multicolumn{13}{|c|}{ Humidity $\left(\mathrm{g} \mathrm{kg}^{-1}\right)$} \\
\hline iter1 & 0.09 & 1.89 & 0.87 & 0.02 & 1.89 & 0.85 & 0.24 & 1.90 & 0.78 & 0.08 & 1.77 & 0.81 \\
\hline iter2 & 0.06 & 1.87 & 0.88 & 0.01 & 1.88 & 0.86 & 0.19 & 1.87 & 0.79 & 0.03 & 1.76 & 0.81 \\
\hline iter $2 \mathrm{~m}$ & 0.04 & 1.89 & 0.87 & -0.03 & 1.91 & 0.85 & 0.20 & 1.89 & 0.78 & 0.02 & 1.76 & 0.80 \\
\hline
\end{tabular}

${ }^{\mathrm{a}} \mathrm{IOA}=1-\left[\sum_{i=1}^{n}\left(M_{i}-O_{i}\right)^{2} / \sum_{i=1}^{n}\left(\left|M_{i}-\bar{O}\right|+\left|O_{i}-\bar{O}\right|\right)^{2}\right]$ (dimensionless), where $M_{i}$ is the modeled value at site/time $i, O_{i}$ is the observed value at site/time $i, n$ is the number of paired modeled-observed values, and $\bar{O}$ is the mean observed value.

meteorological fields in terms of either the diurnal trends (Fig. 2) or monthly averaged performance statistics (Table 3). Therefore, paired $t$ tests were executed to examine whether the hourly statistics in one simulation are different from the other with statistical significance (i.e., $p$ value $<0.05$ with $95 \%$ confidence interval, as marked in Figs. S2 and S3 in the online supplemental material). According to the null hypothesis and alternative hypothesis in the $t$ tests, along with the meaning of changes in absolute bias, RMSE, and IOA, $p$ values were interpreted as a sign of improving or deteriorating performance, with neutral (blank in Table 4) referring to statistically insignificant difference relative to the baseline.

Consistent with the diurnal plots and performance statistics, the paired $t$ tests suggest that the modified second iteration does not make any statistically

TABLE 4. Intercomparisons of model performance in terms of statistically significant changes as indicated by the $p$ value $<0.05$ with $95 \%$ confidence interval in paired $t$ tests for the first (iter1), second (iter2), and modified second (iter2m) iterations over the 4-km domain from 1 Jul to 1 Aug 2011 (UTC).

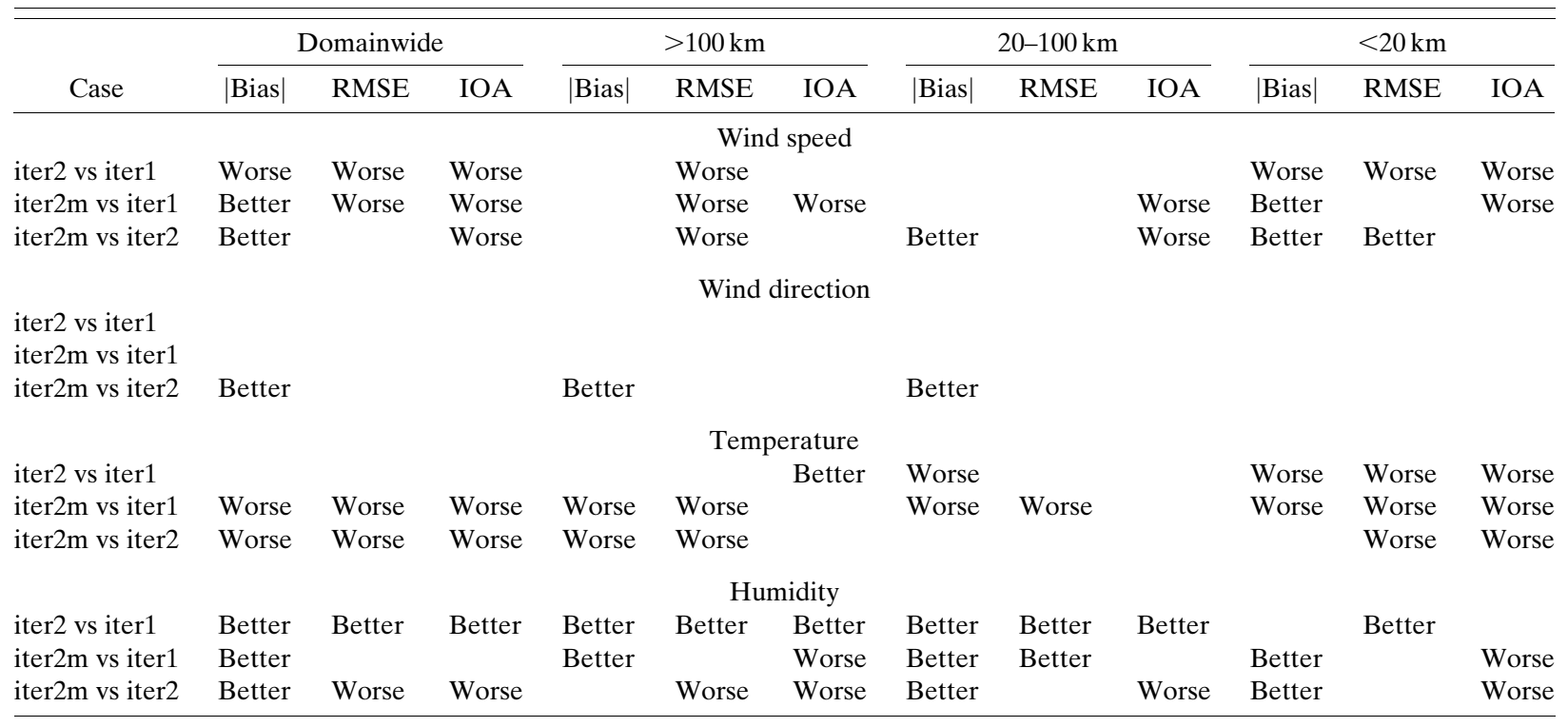


significant improvements except for a few variables, for example, lower biases for humidity in iter $2 \mathrm{~m}$ relative to iter1 or iter2 (Table 4). However, some variables show mixed performance changes-depending on which statistics are used. For instance, the domainwide wind speed seems to perform better in iter $2 \mathrm{~m}$ than in iter 1 in terms of lower bias ( $p=0.023$; Fig. S2), whereas iter $2 \mathrm{~m}$ shows higher RMSE ( $p=0.016$; Fig. S3) and lower IOA $(p=0.000$; Fig. S2), indicating worse performance. Although the iterative analysis was designed to yield better surface temperature, simulated temperature in the modified second iteration is not as good as in the initial iteration.

Although the second iterations perform statistically better for some variables, the improvements are not as significant as those reported by Appel et al. (2014) in the iterative WRF analysis applied to the Chesapeake Bay region. This warrants further analysis of the errors in the large-scale analyses, which was not attempted here. Since the iterative technique is designed to replace the large-scale analysis with the finescale simulation it would be more effective in regions where the errors in the finescale simulation are much smaller than the errors in the large-scale analysis. A more complex finescale structure of the physical atmosphere caused by the more jagged coastline and rougher topography of the Chesapeake Bay relative to the Great Lakes may be leading to greater differences between the finescale simulation and the large-scale analysis and hence to greater improvements with iterative nudging in the Chesapeake Bay region. Also, other years may provide more substantive impacts of the iterative technique. As modelers are simulating recent intensive field studies (e.g., the 2017 LMOS or 2018 Long Island Sound Tropospheric Ozone Study), such techniques should continue to be evaluated for their ability to maintain the details of the lake/sea- and land-breeze structures in other regions and other years.

\section{Vertical nudging strategies: Model performance and impact on nocturnal low-level jets}

As noted in the introduction, nocturnal low-level jets can significantly impact the transport and growth of pollutant plumes (McNider et al. 1988; Banta et al. 1998; NESCAUM 2006). As discussed below, models such as WRF have the physics to potentially capture the LLJ. Models have also consistently shown the ability to produce LLJ in a variety of geographies (e.g., Hu et al. 2012; Storm et al. 2009; Nielsen-Gammon et al. 2010). However, more recently it has been found that nudging strategies used in air quality studies may inhibit the natural LLJ development (Gilliam et al. 2012; Godowitch et al. 2011). Here we discuss the ability of models to capture the nocturnal LLJ and the explicit impact of nudging strategies on the LLJ.

As discussed by Otte (2008), there is considerable evidence that FDDA nudging can improve meteorological and air quality model performance in retrospective studies. However, since finescale modeling is supposed to improve mesoscale structure, which may be driven by boundary layer gradients, there has been reluctance to nudge within the boundary layer. For example, Stauffer et al. (1991) especially cautioned against nudging point measurements of surface temperatures and recommended assimilation of surface winds and moistures throughout the PBL according to an idealized conceptual model of the boundary layer structure. They also noted even small changes may produce imbalances in the surface energy budget that the finescale model is solving. Thus, many air quality modeling studies have chosen the option in WRF of not nudging in the boundary layer even if it might provide some improvement in surface wind performance (at least where wind observations are made).

Here we explicitly explore how FDDA nudging above the boundary layer may also cause harm to the temporal mesoscale structure as manifested in the nocturnal lowlevel jet (Blackadar 1957). The PBL depth is very temporally dynamic under medium to light winds. At night when the PBL depth becomes small, if you are nudging above the PBL you are then nudging in the residual layer of the previous daytime boundary layer. The impact of FDDA on low-level jets was evidently first discussed in Shafran et al. (2000), which cautioned against nudging below a specific model level. Shafran et al. (2000) noted that the nocturnal LLJ was not resolved in the standard National Weather Service (NWS) rawinsonde observations but was found in special profiler observation obtained under the 1991 LMOS. Thus, it found that nudging to NWS wind analyses below $1500 \mathrm{~m}$ would obscure the LLJ. While Shafran et al. (2000) was prescient in recognizing the problems with nudging to NWS analyses in the vertical region encompassing the formation of the LLJ, there were no specific examples given of the impact on the LLJ. More recently Godowitch et al. (2011) showed as part of a more general air quality study that LLJs may be adversely impacted by FDDA strategies used by the U.S. Environmental Protection Agency (EPA) and many in the air quality community. Specifically, Gilliam et al. (2012), in a comprehensive analysis of model wind performance in WRF in comparison with nontraditional profiler and radar, showed that nudging strategies traditionally employed by EPA degraded model performance.

The nocturnal boundary layer is very shallow (from tens of meters to a few hundred meters depending on 
wind speed and roughness; McNider et al. 2012) as compared with the daytime boundary layer that is often $1-2 \mathrm{~km}$ in depth. As noted in Shafran et al. (2000), the residual layer between the shallow nocturnal boundary layer and the old daytime boundary layer is where the LLJ develops. As discussed first by Blackadar (1957), the LLJ develops overnight under conditions of clear skies and relatively light geostrophic winds where a stable boundary layer can develop [note these are often conditions for air pollution episodes (Wallace and Hobbs 1977)]. As the nighttime boundary layer stabilizes, momentum fluxes to the surface are reduced. Thus, the layer of air above the shallow nocturnal boundary layer has reduced friction and begins to accelerate. As the air accelerates, Coriolis forces turn the unbalanced winds leading to an inertial oscillation as the layer seeks a new geostrophic balance. Thus, an evolving LLJ is a persistent part of the nocturnal boundary layer under medium to light winds and clear skies, which are also characteristic of pollution events. As discussed by McNider and Pielke (1981), baroclinic zones produced by heated terrain and land water contrasts alters the geostrophic wind to which the layer is seeking balance, and can produce a very strong jet if the thermal wind produced by the baroclinicity is in the same direction as the large-scale geostrophic wind. For the western shores of Lake Michigan, a southerly large-scale wind would typically be enhanced by the lake-induced daytime baroclinicity. As shown by McNider and Pielke (1981), the reversal in baroclinicity at night is too shallow to overcome the daytime increase in the pressure gradient. From an air pollution perspective, as discussed by McNider et al. (1988) and Gupta et al. (1997), these nighttime winds can be the dominant process for controlling plume width through shear distorting the plume. Under light winds typical of air pollution events, they also can be the dominant mechanism for exporting urban emissions in the residual layer above the stable boundary layer.

Rawinsonde times (0000 and 1200 UTC) in the eastern and central United States generally correspond to daylight hours in summer. Thus, as described by Shafran et al. (2000) and Godowitch et al. (2011), rawinsondes are not likely to resolve LLJs. Aircraft observations are included in some larger-scale analyses, but their frequency overnight when the LLJ forms is limited (Moninger et al. 2006). Thus, in the absence of other special data or model input to the analysis, the LLJ may not be captured in the larger-scale analysis. Therefore, nudging to observation-based analyses below a certain level of the atmosphere may remove or reduce the strength of the LLJ.

Shafran et al. (2000) introduced the concern with applying FDDA in the residual layer above the nocturnal boundary but below the old daytime mixed layer. Also, this work set in place the option in MM5 (the predecessor of WRF) that was continued in WRF to allow nudging above a certain model vertical level through the "zfac" parameter. A more thorough discussion of the issue and possible trade-offs in terms of surface meteorological and air quality model performance is important for the air quality community. Here we provide an explicit evaluation of nudging strategies in terms of surface performance and model performance in the residual layer in case studies in the Great Lakes region. Also, the impact on air quality for two different vertical nudging strategies is provided using the CMAQ model (Byun and Schere 2006).

\section{a. Surface evaluation}

Experiments were carried out for the $12-\mathrm{km}$ resolution July 2011 WRF simulation described in section 2 above. Two cases were selected-one with nudging above the PBL (note that the PBL height is dynamic and that it is treated that way in WRF) and a second case in which nudging was only carried out above $2 \mathrm{~km}$ (more precisely above layer 19 , which extends approximately to $2-\mathrm{km}$ altitude). As a caveat, it is noted that if the PBL depth is greater than $2 \mathrm{~km}$ then nudging would be carried in the PBL. To clarify the cases, the case with nudging above the PBL for the daytime would likely result in nudging only above $1-2 \mathrm{~km}$ because of the depth of the summer daytime boundary layer. However, because the nocturnal boundary layer is so shallow at night, the case of nudging above the PBL would likely yield nudging in the residual layer between the nighttime PBL and the old daytime PBL. There are minimum values for stable PBLs sometimes tied to minimum momentum stress values. These are PBL-scheme dependent but are consistent with CMAQ if the PleimAsymmetric Convective Model, version 2 (ACM2), scheme is used (see McNider et al. 2018). As discussed above, this is the vertical domain in which the LLJ would likely develop. Of course, daytime PBL depths over the cold lakes would be much lower. The details of the case with nudging above the boundary layer are given as the initial-iteration case in the iterative analysis in section 2. Standard model evaluation statistics were calculated for the two cases.

Figure 3 shows the meteorological evaluation. Performance in temperature and humidity was very similar for the two nudging strategies. Wind speed statistics were slightly improved when nudging was applied above the PBL compared to only nudging above $2 \mathrm{~km}$ (layer 19 of the model). However, for both nudging cases there is a significant overprediction of wind speeds at night. This may be due to too much mixing in the modeled 
— Obs -... Sim12 --- Sim12_nudging19
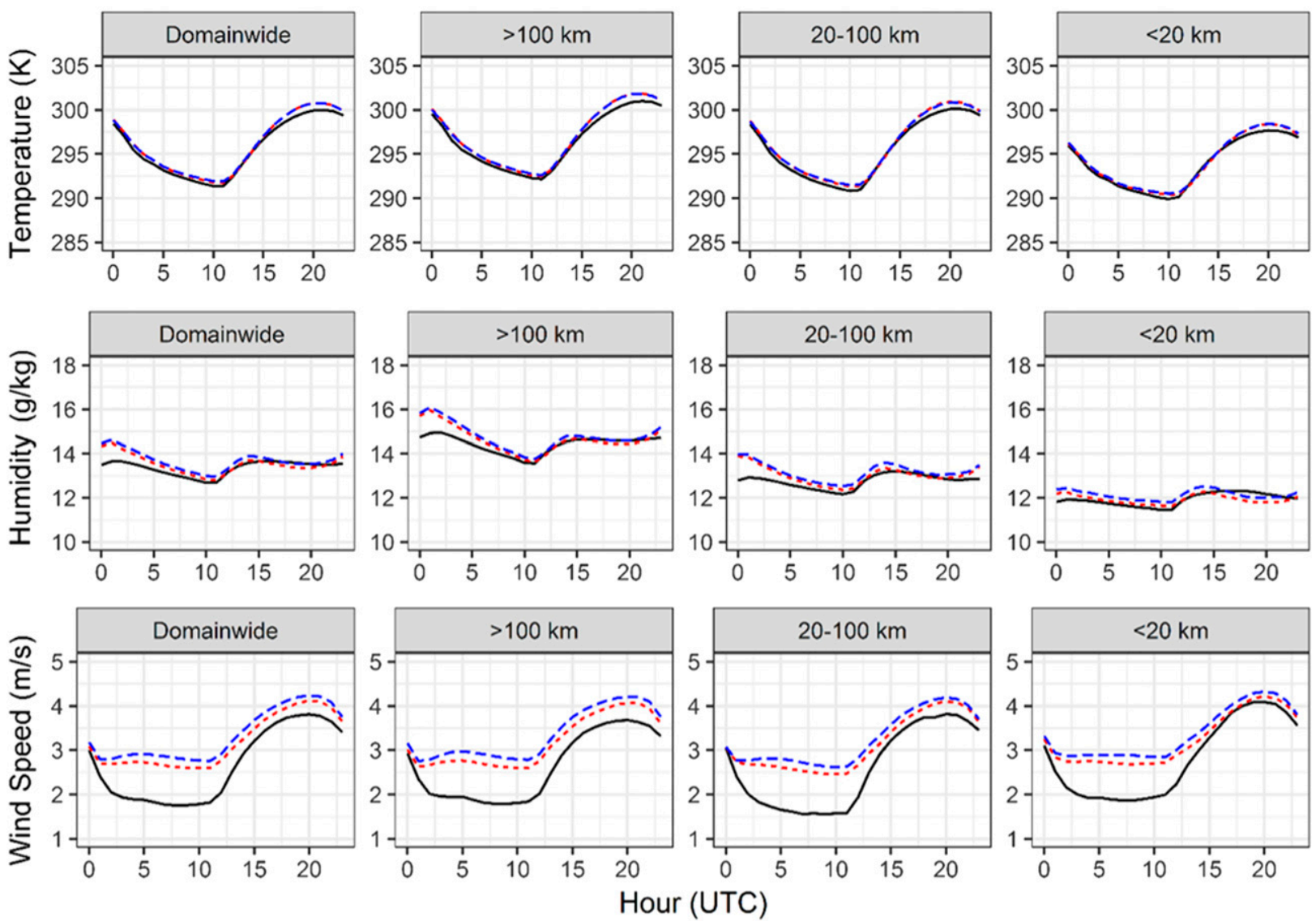

FIG. 3. Diurnal trends of observed (solid line) and simulated (with 12-km grid resolution) temperature, humidity and wind speed at the surface with nudging above the PBL (red dashed line) and above $2 \mathrm{~km}$ (blue dashed line) within the 4-km grid domain shown in Fig. 1 for the period from $1 \mathrm{Jul}$ to 1 Aug 2011. The number of observational sites for each site category is the same as in Fig. 2. Note that UTC is $5 \mathrm{~h}$ ahead of local time (CDT); i.e., 1700 UTC corresponds to local noon.

stable boundary layer (see McNider et al. 2018; Savijärvi 2009) and may be independent of nudging strategies. The strategy of only nudging above $2 \mathrm{~km}$ performed as expected, however, and significantly improved the LLJ, as will be discussed below.

\section{b. Upper-level wind evaluation}

To evaluate the nudging strategies, model wind speed profiles were produced at three NOAA Profile Network (NPN) sites (Fig. 4). As noted above, the standard rawinsonde times in the Midwest do not capture the peak in the LLJ. However, in 2011 the NPN was still operational, and it included sites over the Great Plains and parts of the Midwest. The NPN was decommissioned in 2014, but the data are still available at MADIS (https:// madis.ncep.noaa.gov/). Most of the NPN wind profilers are UHF Doppler radars that can measure vertical profiles of horizontal winds. These profilers have a range extending from $500 \mathrm{~m}$ to $3 \mathrm{~km}$ above ground level with 250-m resolution.

Figure 5 shows the vertical wind profiles from the model for the two different nudging strategies at the three profiler observation sites. As discussed above, it appears in Fig. 5 that the nudging within the residual layer (between the nocturnal boundary layer and previous day's daytime boundary layer) suppresses the formation of the LLJ. The model LLJ forms mostly below $500 \mathrm{~m}$, with the peak of the jet generally at 200-300 m. However, because the NOAA operational network had its lowest observational level at approximately $570 \mathrm{~m}$, there are very few observations in the region of the model LLJ. Only station WLCI3 appears to capture the upper part of the jet in agreement with the model. Thus, it appears that concerns about nudging above the PBL suppressing the LLJ are valid. 


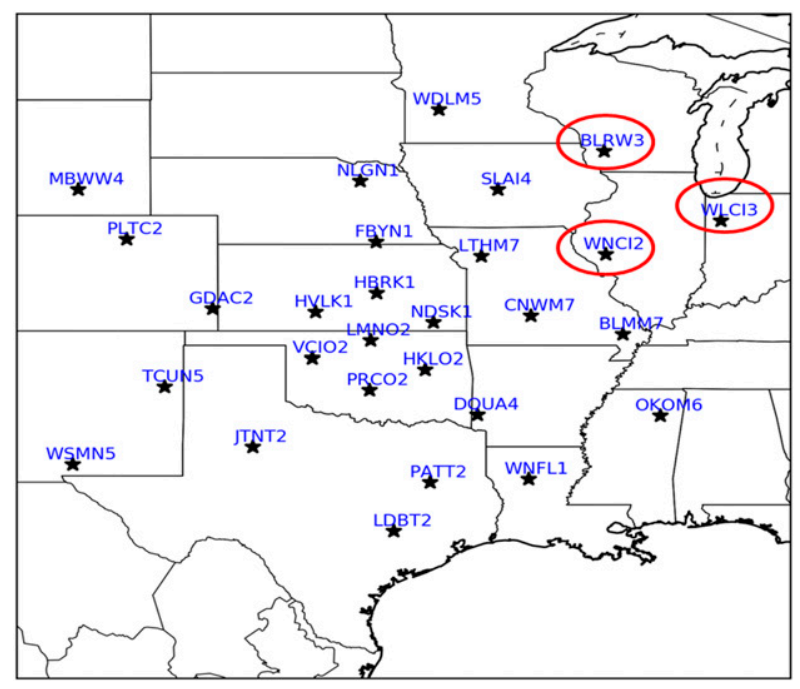

FIG. 4. Locations of NOAA NPN profiler sites. Model comparative statistics were based on all sites. Red circled stations show locations where specific low-level jets were compared with model nudging strategies.

In examining the winds above the LLJ region, it appears in Fig. 5 that the model winds are further from the observed profiles for the case of nudging above $2 \mathrm{~km}$. Figure 6 shows the statistical evaluation in comparison with the profiler observations at $570 \mathrm{~m}$, mostly above the LLJ formation. Thus, while nudging above $2 \mathrm{~km}$ may allow the LLJ to develop, not nudging in the region above $500 \mathrm{~m}$ may deteriorate wind performance in this region.

In retrospect, it seems that, on the basis of these evaluations, a strategy to nudge above $1 \mathrm{~km}$ (or even 500 or $750 \mathrm{~m}$ ) rather than above $2 \mathrm{~km}$ might be a better strategy. This would preserve the formation of the LLJ yet improve wind performance above the LLJ. However, such refinement may be better tested where good radar boundary layer profilers are available.

\section{c. Air quality impact of nudging strategies}

In addition to the meteorological analysis, the CMAQ model was run for the two vertical nudging strategies above. The emissions inputs and CMAQ model configuration were set as the same in the two nudging cases; only meteorological inputs differed. A detailed description of the CMAQ model configuration can be found in Qin et al. (2019). Figure 7 shows the ozone performance for the two cases. It shows that the case of nudging only above $2 \mathrm{~km}$ slightly improves ozone performance. However, note that the performance is improved in the daytime [a domainwide overestimation of 5 parts per billion (ppb) instead of 6 $\mathrm{ppb}]$ and not in the nighttime.

Figure 8 shows the spatial differences in ozone between the case of nudging above PBL and nudging above $2 \mathrm{~km}$. It shows that there are areas where the difference in nudging strategies changed (increased or decreased) simulated ozone. The biggest differences are over Lake Michigan. This may be due to the fact that the cool lake generally has a stable boundary layer both day and night so that the nudging near the surface is reduced and greater lake mesoscale structure is retained in the case of no nudging below $2 \mathrm{~km}$. However, as discussed in McNider et al. (2018), it may be due to low-level shear differences in the two nudging cases that are producing different mixing environments over the lake.

Figure 9 shows the difference in the ozone mean bias between the two model nudging cases in the $12-\mathrm{km}$ resolution simulation. It shows that the case with nudging only above $2 \mathrm{~km}$ improves the model performance over much of the eastern United States and especially in the Midwest. Note the performance is especially improved along the periphery of Lake Michigan. The improvement may be in part due to the preservation of the LLJ. It may also show that preservation of the LLJ may be more important than the deterioration in wind performance above the LLJ where perhaps there is less ozone and fewer precursors.

\section{d. Broader implications of the LLJ to air quality}

Examples have shown (see McNider and Pour-Biazar 2019) that the LLJ appears to be a significant factor in exporting both emissions and precursors overnight out of source areas. Models have consistently underestimated $\mathrm{NO}_{2}$ column values in rural areas and overestimated $\mathrm{NO}_{2}$ columns in urban areas relative to satellite column $\mathrm{NO}_{2}$ (see Castellanos et al. 2011; Canty et al. 2015; Kuhlmann et al. 2015; Goldberg et al. 2017). Canty et al. (2015) concluded that the CMAQ model may underestimate the interstate transport of nitrogen oxides $\left(\mathrm{NO}_{x}\right)$ and/or nitric oxide (NO) reservoirs. Understating the LLJ, which may provide the main export of pollutants out of urban areas under light winds, would be consistent with this finding.

As shown by McNider et al. (1988), in addition to export out of urban areas, the LLJ can also control the horizontal growth rate of point source plumes. $\mathrm{Ne}$ glecting the shear in the LLJ may make plumes much narrower and change their long-range impacts. The Clean Air Act's "good neighbor" provision requires EPA and state governments to address interstate transport of air pollution that affects downwind states' ability to attain and maintain NAAQS. In addition, the "regional haze rule" requires the states to implement plans for reducing their contributions to manmade haze in pristine (Class I) areas. Thus, the LLJ may be very important for state implementation plans. 
(a)
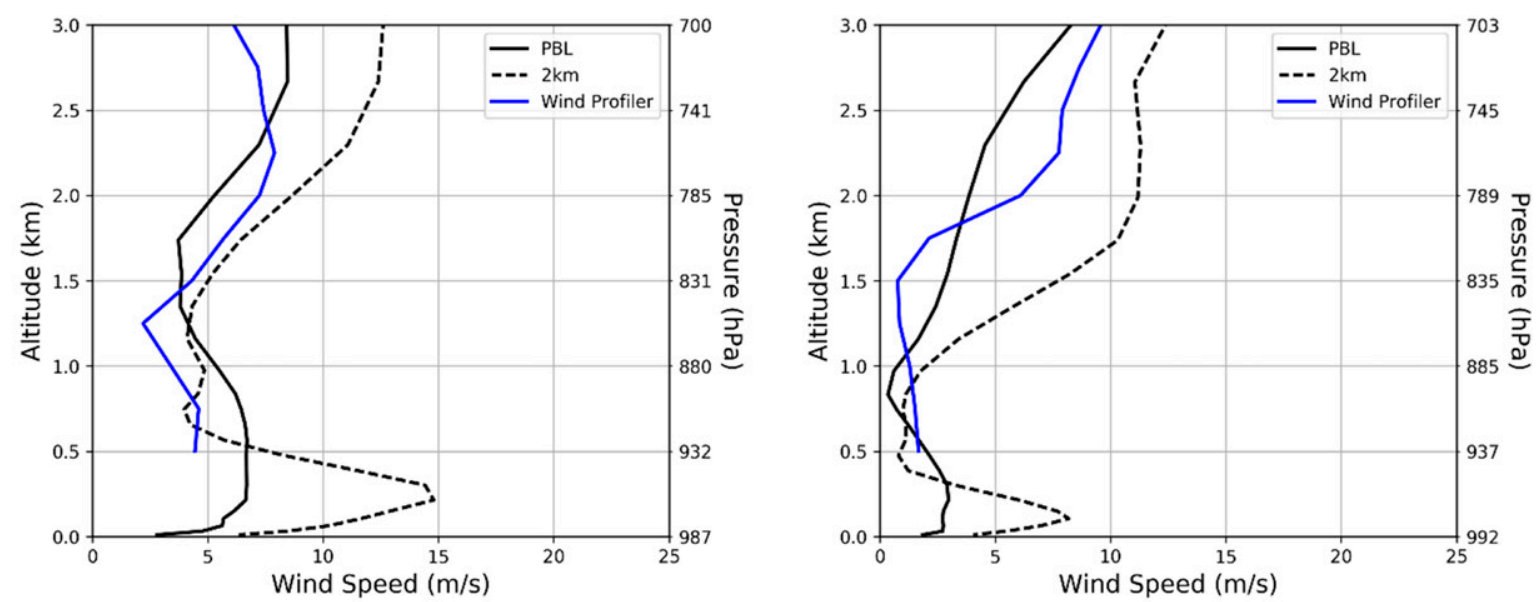

(b)
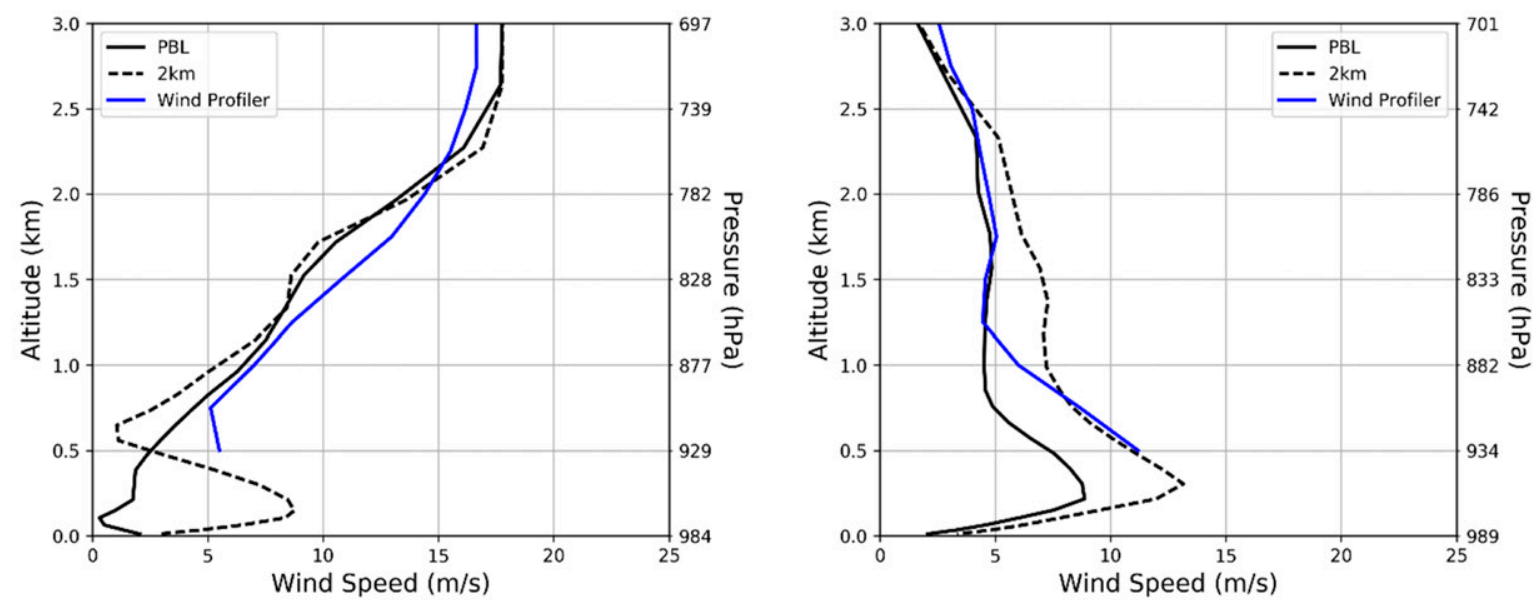

(c)
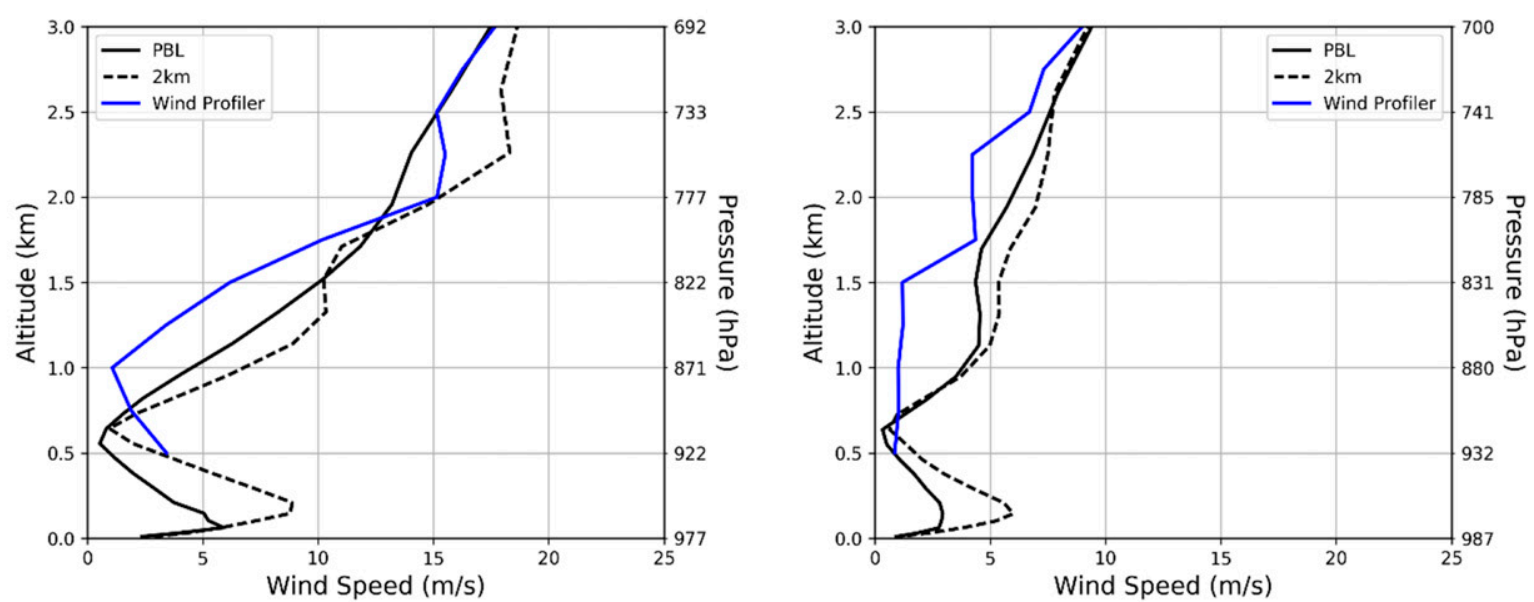

FIG. 5. Model and observed wind profiles for (a) WNCI2 (western Illinois) at (left) 0300 UTC (2100 LST) 17 Jun 2011 and (right) 0600 UTC (0000 LST) 4 Jul 2011, (b) WLCI3 (northern Indiana) at (left) 0400 UTC (2200 LST) 17 Jun 2011 and (right) 0900 UTC (0300 LST) 24 Jul 2011, and (c) BLRW3 (southwestern Wisconsin) at (left) 0400 UTC (2200 LST) 17 Jun 2011 and (right) 1000 UTC (0400 LST) 29 Jun 2011. The black solid line is for nudging above the PBL, the black dashed line is for nudging only above $2 \mathrm{~km}$, and the blue solid line is the profiler observation. 

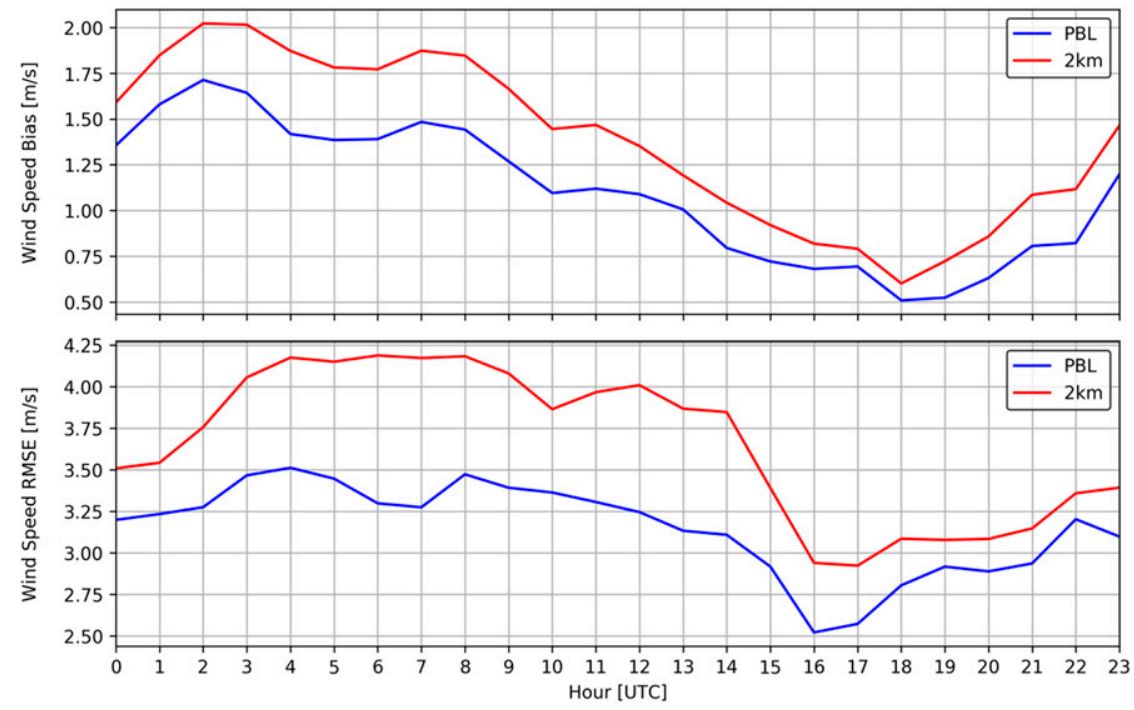

FIG. 6. Comparative statistics between model nudging strategies and profiler observations at $570 \mathrm{~m}$ AGL: (top) wind speed bias and (bottom) RMSE. The blue line is for nudging only above the PBL, and the red line is for nudging only above $2 \mathrm{~km}$.

\section{Summary and conclusions}

This study examines the impact of nudging strategies on meteorological inputs for air quality modeling. Two areas are examined-the impact of iterative nudging on meteorological performance and the impact of vertical nudging strategies on LLJ development and impact on air quality simulations. These are summarized separately below.

\section{a. Iterative FDDA}

Examination of an iterative FDDA nudging technique proposed by Appel et al. (2014) for 2011 in the Great Lakes region did not show significant improvements in model performance. This lack of significant positive impact of the iterative technique in the Great Lakes as compared with the significant results found by Appel et al. (2014) for the Chesapeake area is perhaps, in part, due to differences in geographic complexity. The Chesapeake Bay area has a very complex water boundary setting with bays, rivers, and thin barrier islands creating finescale structure land-water thermal contrasts. In addition, R. C. Gilliam (2017, personal communication) has noted that the topography of the Appalachians may have played a role in the differences between iterations. In contrast, along Lake Michigan, terrain is much flatter and land-water boundaries are — Obs $\cdots$ Sim_base - - Sim_nudging_above_2km
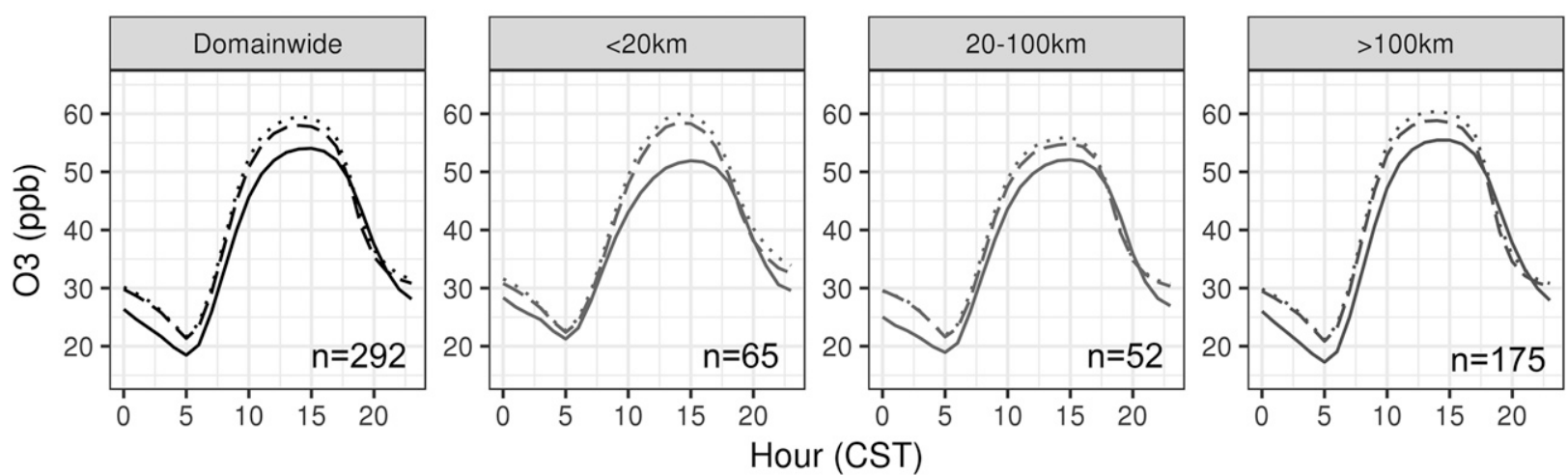

FIG. 7. Diurnal trends of surface $\mathrm{O}_{3}$ over the Great Lakes region in July 2011 . The solid line is for the observation, the dotted line is for the base simulation with nudging above the PBL, and the dashed line is for the simulation with nudging above $2 \mathrm{~km}$. 
(a)

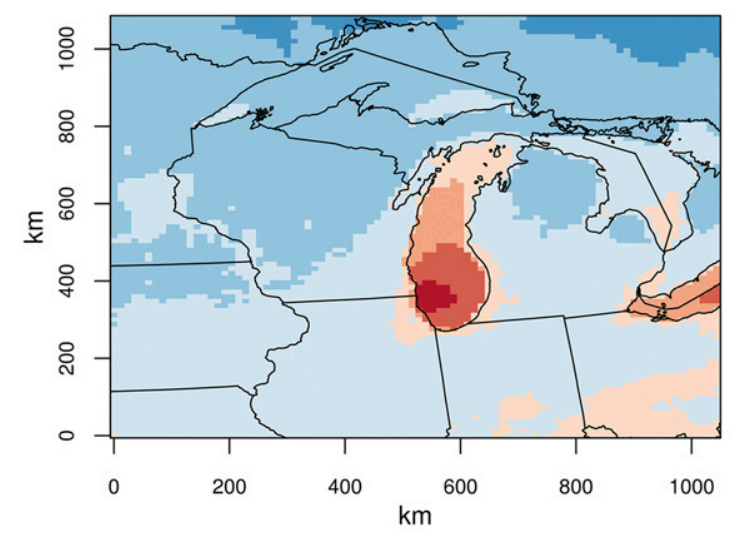

(c) $\triangle$ MDA8 O3 (nudging_above_2km-base) (b) MDA8 03 (nudging above $2 \mathrm{~km}$ )

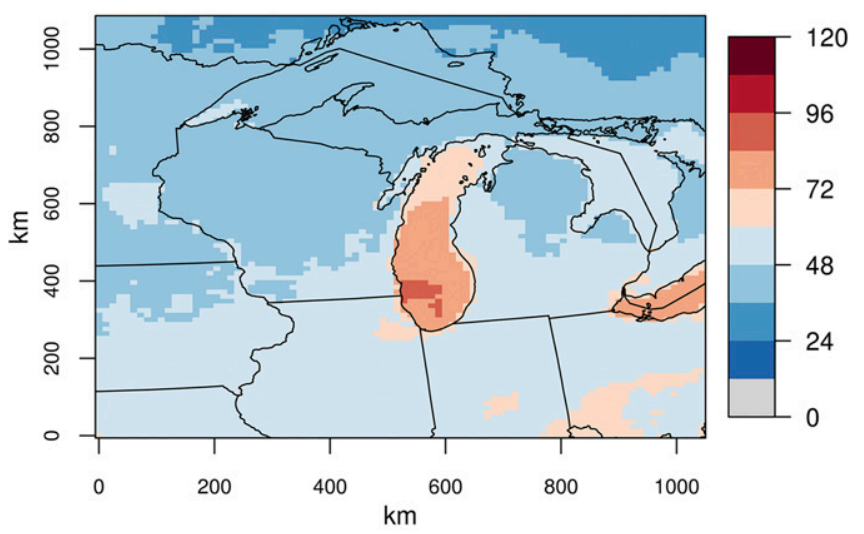

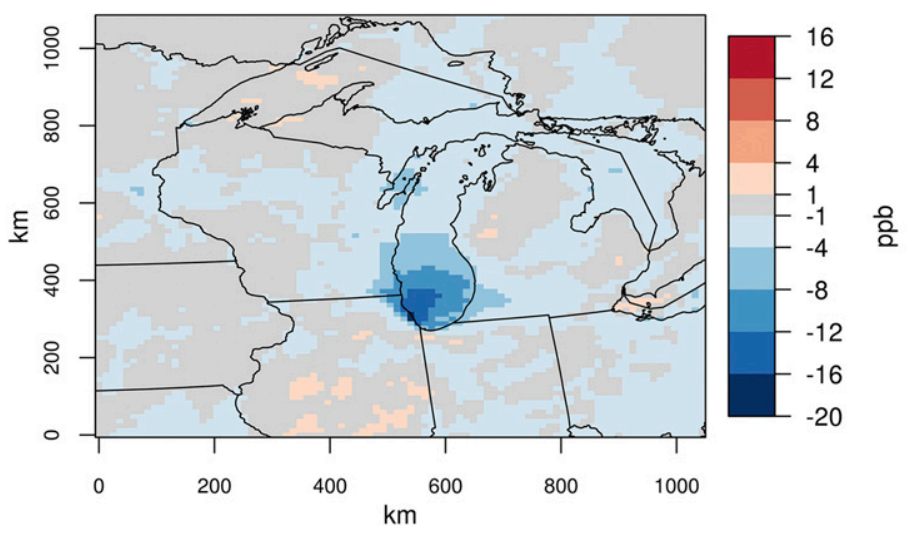

FIG. 8. Daily maximum 8-h-average $\mathrm{O}_{3}$ in the July 2011 simulations with (a) nudging above the PBL and (b) nudging only above $2 \mathrm{~km}$, and (c) their difference [(b) minus (a)].

less complex. Although at this point there are no controlled experiments from other areas to support this conclusion as the reason for the iterative results, the differences in land-water boundaries and topographic complexities probably cannot be discounted.

\section{b. Vertical nudging strategies}

While models such as WRF have the requisite physics to produce the Blackadar low-level jet, it has become apparent that the use of retrospective nudging strategies used in many air quality studies can inhibit the formation of the LLJ. The case with no nudging in the model boundary layer (a common nudging strategy) showed slight improvement in surface wind performance (it slightly reduced a large positive bias especially at night) compared to the case with no nudging below $2 \mathrm{~km}$. However, this was at the expense of reducing the magnitude of the nocturnal low-level jet as compared to when nudging was restricted to above $2 \mathrm{~km}$ (see also Shafran et al. 2000; Gilliam et al. 2012). In the evaluation of ozone performance, the case with no nudging below $2 \mathrm{~km}$ improved the performance, especially along the shores of Lake Michigan. This may indicate the importance of the LLJ in air quality transport or a difference in diagnosed mixing due to the two different nudging strategies. Note that the present study was meant to provide an initial examination of the impact of vertical nudging on LLJ development and air quality. In retrospect, a minimum $2-\mathrm{km}$ cutoff to apply nudging may be too high, and $1.5 \mathrm{~km}$ as used in Shafran et al. (2000) may be better, at least in the eastern United States. However, refinements in details of the nudging strategy should be carried out where boundary layer profilers can provide observations.

More research is needed to understand the importance of the LLJ to current air quality issues and impact on control strategies. As mentioned above, it may have relevance to current underprediction of $\mathrm{NO}_{2}$ column values in rural areas relative to satellite data (Canty et al. 2015). Reduction in the amplitude of the LLJ may also affect background values in urban control strategy evaluations and be important to long-range transport for regional haze or good neighbor state implementation plans. Without the LLJ and its export of ozone and 


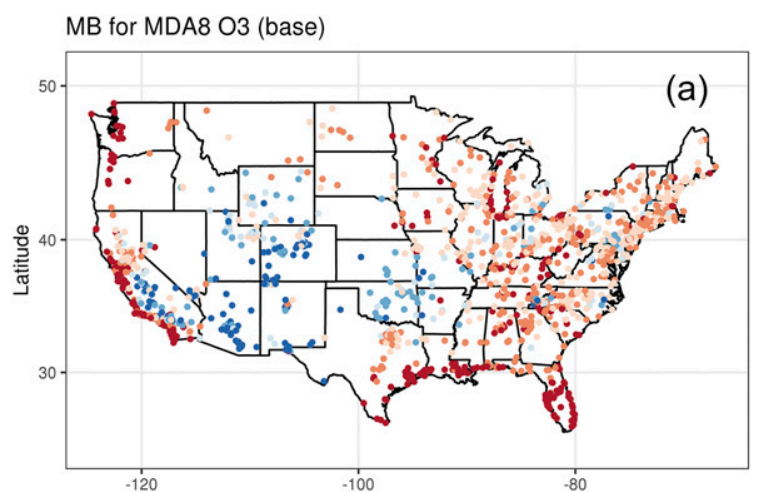

$\Delta|\mathrm{MB}|$ for MDA8 O3 (nudging19-base)

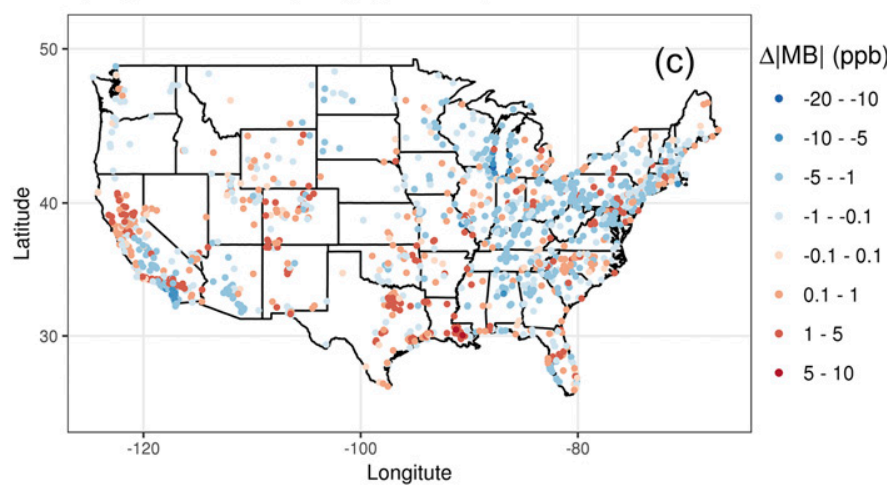

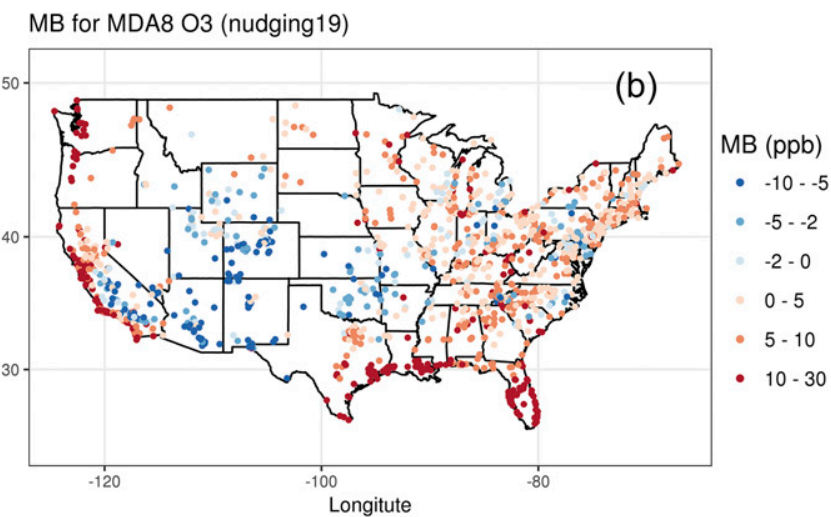

precursors out of urban areas, local emission reductions may appear to be more effective than they actually are. In summary, we believe the impact of nudging on the LLJ and stable boundary layer mixing is a model component that should be of interest to the air quality research and regulatory community since it addresses a key model discrepancy.

Acknowledgments. This research was sponsored in part by the Electric Power Research Institute (EPRI), the NASA Air Quality (AQAST) and Health and Air Quality (HAQAST) Applied Sciences Teams, and the State of Texas Air Quality Research Program (AQRP). The findings in this research do not necessarily reflect the views of EPRI, NASA, or AQRP. We thank program managers John Haynes (NASA AQAST/HAQAST) and Elena McDonald (TX AQRP) for their support.

\section{REFERENCES}

Appel, W., R. Gilliam, J. Pleim, G. Pouliot, D. Wong, C. Hogrefe, S. Roselle, and R. Mathur, 2014: Improvements to the WRFCMAQ modeling system for fine-scale air quality simulations. EM, 14 (9), 16-21, http://pubs.awma.org/flip/EM-Sept-2014/ appel.pdf.

Banta, R. M., and Coauthors, 1998: Daytime buildup and nighttime transport of urban ozone in the boundary layer during a stagnation episode. J. Geophys. Res., 103, 22 519-22544, https://doi.org/10.1029/98JD01020.

Blackadar, A. K., 1957: Boundary layer wind maxima and their significance for the growth of nocturnal inversions. Bull. Amer. Meteor. Soc., 38, 283-290, https://doi.org/10.1175/15200477-38.5.283.

Byun, D., and K. L. Schere, 2006: Review of the governing equations, computational algorithms, and other components of the Models-3 Community Multiscale Air Quality (CMAQ) modeling system. Appl. Mech. Rev., 59, 51-77, https://doi.org/10.1115/1.2128636.

Canty, T. P., and Coauthors, 2015: Ozone and $\mathrm{NO}_{x}$ chemistry in the eastern US: Evaluation of $\mathrm{CMAQ} / \mathrm{CB} 05$ with satellite (OMI) data. Atmos. Chem. Phys., 15, 10965, https://doi.org/ 10.5194/acp-15-10965-2015.

Carras, J. N., and D. J. Williams, 1981: The long-range dispersion of a plume from an isolated point source. Atmos. Environ., 15, 2205-2217, https://doi.org/10.1016/0004-6981(81)90252-3.

Castellanos, P., L. T. Marufu, B. G. Doddridge, B. F. Taubman, J. J. Schwab, J. C. Hains, S. H. Ehrman, and R. R. Dickerson, 2011: Ozone, oxides of nitrogen, and carbon monoxide during pollution events over the eastern United States: An evaluation of emissions and vertical mixing. J. Geophys. Res., 116, D16307, https://doi.org/10.1029/2010JD014540.

Cleary, P. A., and Coauthors, 2015: Ozone distributions over southern Lake Michigan: Comparisons between ferry-based observations, shoreline-based DOAS observations and model forecasts. Atmos. Chem. Phys., 15, 5109-5122, https://doi.org/ 10.5194/acp-15-5109-2015.

EPA, 2018: 8-Hour Ozone Nonattainment Areas (2008 Standard). Accessed 8 February 2019, https://www3.epa.gov/airquality/ greenbook/map8hr_2008.html. 
Foley, T., E. A. Betterton, P. R. Jacko, and J. Hillery, 2011: Lake Michigan air quality: The 1994-2003 LADCO Aircraft Project (LAP). Atmos. Environ., 45, 3192-3202, https://oi.org/10.1016/ j.atmosenv.2011.02.033

Gifford, F. A., 1983: Author's reply. Atmos. Environ., 17, 196-197, https://doi.org/10.1016/0004-6981(83)90030-6.

Gilliam, R. C., and J. E. Pleim, 2010: Performance assessment of new land-surface and planetary boundary layer physics in the WRF-ARW. J. App. Meteor. Climatol., 49, 760-774, https:// doi.org/10.1175/2009JAMC2126.1.

_ J. M. Godowitch, and S. T. Rao, 2012: Improving the horizontal transport in the lower troposphere with four dimensional data assimilation. Atmos. Environ., 53, 186-201, https://doi.org/10.1016/j.atmosenv.2011.10.064

Godowitch, J. M., R. C. Gilliam, and S. T. Rao, 2011: Diagnostic evaluation of ozone production and horizontal transport in a regional photochemical air quality modeling system. Atmos. Environ., 45, 3977-3987, https://doi.org/10.1016/ j.atmosenv.2011.04.062.

Goldberg, D. L., L. N. Lamsal, C. P. Loughner, W. H. Swartz, Z. Lu, and D. G. Streets, 2017: A high-resolution and observationally constrained $\mathrm{OMI} \mathrm{NO}_{2}$ satellite retrieval. Atmos. Chem. Phys., 17, 11 403-11 421, https://doi.org/10.5194/acp-17-11403-2017.

Gupta, S., R. McNider, M. Trainer, R. J. Zamora, K. Knupp, and M. Singh, 1997: Nocturnal wind structure and plume growth rates due to inertial oscillations. J. Appl. Meteor., 36, 1050-1063, https://doi.org/10.1175/1520-0450(1997)036<1050 NWSAPG $>2.0 . \mathrm{CO} ; 2$.

Hu, X.-M., D. C. Doughty, K. J. Sanchez, E. Joseph, and J. D. Fuentes, 2012: Ozone variability in the atmospheric boundary layer in Maryland and its implications for vertical transport model. Atmos. Environ., 46, 354-364, https://doi.org/10.1016/ j.atmosenv.2011.09.054.

Iacono, M. J., J. S. Delamere, E. J. Mlawer, M. W. Shephard, S. A. Clough, and W. D. Collins, 2008: Radiative forcing by longlived greenhouse gases: Calculations with the AER radiative transfer models. J. Geophys. Res., 113, D13103, https://doi.org/ 10.1029/2008JD009944.

Kain, J., 2004: The Kain-Fritsch convective parameterization: An update. J. Appl. Meteor., 43, 170-181, https://doi.org/10.1175/ 1520-0450(2004)043<0170:TKCPAU>2.0.CO;2.

Kuhlmann, G., Y. F. Lam, H. M. Cheung, A. Hartl, J. C. H. Fung, P. W. Chan, and M. O. Wenig, 2015: Development of a custom $\mathrm{OMI} \mathrm{NO}_{2}$ data product for evaluating biases in a regional chemistry transport model. Atmos. Chem. Phys., 15, 56275644, https://doi.org/10.5194/acp-15-5627-2015.

Lyons, W. A., and H. S. Cole, 1976: Photochemical oxidant transport: Mesoscale lake breeze and synoptic-scale aspects J. Appl. Meteor., 15, 733-743, https://doi.org/10.1175/15200450(1976)015<0733:POTMLB > 2.0.CO;2.

McNider, R. T., and R. A. Pielke, 1981: Diurnal boundarylayer development over sloping terrain. J. Atmos. Sci., 38, 2198-2212, https://doi.org/10.1175/1520-0469(1981)038<2198: DBLDOS $>2.0 . \mathrm{CO} ; 2$.

_ , and A. Pour-Biazar, 2019: Meteorological modeling relevant to mesoscale and regional air quality applications: A review. J. Air Waste Manage. Assoc., in press.

_ M. D. Moran, and R. A. Pielke, 1988: Influence of diurnal and inertial boundary-layer oscillations on long-range dispersion. Atmos. Environ., 22, 2445-2462, https://doi.org/10.1016/00046981(88)90476-3

_ - and Coauthors, 2012: Response and sensitivity of the nocturnal boundary layer over land to added longwave radiative forcing. J. Geophys. Res., 117, D14106, https://doi.org/10.1029/ 2012JD017578.

- and Coauthors, 2018: Examination of the physical atmosphere in the Great Lakes region and its potential impact on air quality-Overwater stability and satellite assimilation. J. Appl. Meteor. Climatol., 57, 2789-2816, https://doi.org/10.1175/ JAMC-D-17-0355.1.

Mesinger, F., and Coauthors, 2006: North American Regional Reanalysis. Bull. Amer. Meteor. Soc., 87, 343-360, https:// doi.org/10.1175/BAMS-87-3-343.

Meteorological Development Laboratory, 1987: TDL U.S. and Canada Surface Hourly Observations. NCAR Research Data Archive, Computational and Information Systems Laboratory, accessed 8 February 2019, http://rda.ucar.edu/datasets/ds472.0/.

Michelson, S. A., and J. W. Bao, 2008: Sensitivity of low-level winds simulated by the WRF Model in California's Central Valley to uncertainties in the large-scale forcing and soil initialization. J. Appl. Meteor. Climatol., 47, 3131-3149, https://doi.org/ 10.1175/2008JAMC1782.1.

Moninger, W. R., R. D. Mamrosh, N. G. Bay, and W. T. S. Daniels, 2006: Automated weather reports from aircraft: TAMDAR and the U.S. AMDAR FLEET. 12th Conf. on Aviation, Range, and Aerospace Meteorology, Atlanta, GA, Amer. Meteor. Soc., 4.2, https://ams.confex.com/ams/pdfpapers/104483.pdf.

Morrison, H., G. Thompson, and V. Tatarskii, 2009: Impact of cloud microphysics on the development of trailing stratiform precipitation in a simulated squall line: Comparison of oneand two-moment schemes. Mon. Wea. Rev., 137, 991-1007, https://doi.org/10.1175/2008MWR2556.1.

NESCAUM, 2006: The nature of the ozone air quality problem in the ozone transport region: A conceptual description. NESCAUM Doc., 117 pp., https://www.nescaum.org/documents/ 2010_o3_conceptual_model_final_revised_20100810.pdf.

Nielsen-Gammon, J., X.-M. Hu, F. Zhang, and J. Pleim, 2010: Evaluation of planetary boundary layer scheme sensitivities for the purpose of parameter estimation. Mon. Wea. Rev., 138, 3400-3417, https://doi.org/10.1175/2010MWR3292.1.

Otte, T. L., 2008: The impact of nudging in the meteorological model for retrospective air quality simulations. Part II: Evaluating collocated meteorological and air quality observations. J. Appl. Meteor. Climatol., 47, 1868-1887, https://doi.org/10.1175/ 2007JAMC1791.1.

Pleim, J. E., 2007: A combined local and nonlocal closure model for the atmospheric boundary layer. Part I: Model description and testing. J. Appl. Meteor. Climatol., 46, 1383-1395, https://doi.org/ 10.1175/JAM2539.1.

- and A. Xiu, 1995: Development and testing of a surface flux and planetary boundary layer model for application in mesoscale models. J. Appl. Meteor., 34, 16-32, https://doi.org/ 10.1175/1520-0450-34.1.16

$\longrightarrow$, and - 2003: Development of a land surface model. Part II: Data assimilation. J. Appl. Meteor., 42, 1811-1822, https://doi.org/ 10.1175/1520-0450(2003)042<1811:DOALSM > 2.0.CO;2.

— , and R. Gilliam, 2009: An indirect data assimilation scheme for deep soil temperature in the Pleim-Xiu land surface model. J. Appl. Meteor. Climatol., 48, 1362-1376, https:// doi.org/10.1175/2009JAMC2053.1.

Qin, M., and Coauthors, 2019: Improving ozone simulations in the Great Lakes region: The role of emissions, chemistry, and dry deposition. Atmos. Environ., 202, 167-179, https://doi.org/ 10.1016/j.atmosenv.2019.01.025.

Rogers, R. E., A. Deng, D. R. Stauffer, B. J. Gaudet, Y. Jia, S. T. Soong, and S. Tanrikulu, 2013: Application of the Weather 
Research and Forecasting Model for air quality modeling in the San Francisco Bay area. J. Appl. Meteor. Climatol., 52, 1953-1973, https://doi.org/10.1175/JAMC-D-12-0280.1.

Savijärvi, H., 2009: Stable boundary layer: Parametrizations for local and larger scales. Quart. J. Roy. Meteor. Soc., 135, 914921, https://doi.org/10.1002/qj.423.

Shafran, P. C., N. L. Seaman, and G. A. Gayno, 2000: Evaluation of numerical predictions of boundary layer structure during the Lake Michigan Ozone Study. J. Appl. Meteor., 39, 412-426, https:// doi.org/10.1175/1520-0450(2000)039<0412:EONPOB > 2.0.CO;2.

Skamarock, W. C., and Coauthors, 2008: A description of the Advanced Research WRF version 3. NCAR Tech. Note NCAR/ TN-475+STR, 113 pp., https://doi.org/10.5065/D68S4MVH.

Smith, F. B., 1983: Discussion of Gifford (I 982). Atmos. Environ., 17, 194-197, https://doi.org/10.1016/0004-6981(83)90029-X.

Stauffer, D. R., and N. L. Seaman, 1990: Use of four-dimensional data assimilation in a limited-area mesoscale model. Part I: Experiments with synoptic-scale data. Mon. Wea. Rev., 118, 1250-1277, https://doi.org/10.1175/1520-0493(1990)118<1250: UOFDDA $>2.0$.CO;2.

_ and _ 1994: Multiscale four-dimensional data assimilation. J. Appl. Meteor., 33, 416-434, https://doi.org/10.1175/ 1520-0450(1994)033<0416:MFDDA >2.0.CO;2.
,-- , and F. S. Binkowski, 1991: Use of four-dimensional data assimilation in a limited-area mesoscale model. Part II: Effects of data assimilation within the planetary boundary layer. Mon. Wea. Rev., 119, 734-754, https://doi.org/10.1175/15200493(1991)119<0734:UOFDDA > 2.0.CO;2.

Storm, B., J. Dudhia, S. Basu, A. Swift, and I. Giammanco, 2009: Evaluation of the Weather Research and Forecasting (WRF) Model on forecasting low-level jets: Implications for wind energy. Wind Energy, 12, 81-90, https://doi.org/10.1002/we.288.

Taylor, G. I., 1921: Diffusion by continuous movements. Proc. London Math. Soc., 2, 196, https://doi.org/10.1112/PLMS/S220.1.196.

Wallace, J. M., and P. V. Hobbs, 1977: Atmospheric Science: An Introductory Survey. Academic Press, 467 pp.

Xiu, A., and J. E. Pleim, 2001: Development of a land surface model. Part I: Application in a mesoscale meteorological model. J. Appl. Meteor., 40, 192-209, https://doi.org/10.1175/ 1520-0450(2001)040<0192:DOALSM > 2.0.CO;2.

Zhang, D. L., and W. Z. Zheng, 2004: Diurnal cycles of surface winds and temperatures as simulated by five boundary layer parameterizations. J. Appl. Meteor., 43, 157-169, https:// doi.org/10.1175/1520-0450(2004)043<0157:DCOSWA > 2.0.CO;2. 